\title{
Improvement of the analysis methods of the working hours distribution of locomotive crews by the types of train operation in freight traffic
}

\author{
Dmytro Kozachenko ${ }^{1}$, Mykola Berezovyi ${ }^{2}$,Vyacheslav Malashkin ${ }^{2}$, Tetiana Bolvanovska ${ }^{2}$, and Yurii Grimak $^{3}$ \\ ${ }^{1}$ Dnipro National University of Railway Transport, Department of Operation, 41010 Dnipro, Ukraine \\ ${ }^{2}$ Dnipro National University of Railway Transport, Department of Transport Junctions, 41010 Dnipro, Ukraine \\ ${ }^{3}$ Lviv College of Transport Infrastructure of Dnipro National University of Railway Transport named after Academician \\ V. Lazaryan, 79011 Lviv, Ukraine
}

\begin{abstract}
The work is aimed to increase the efficiency of cargo transportation by railway transport by improving the work organization of locomotive crews. The research is based on the methods of organization of operational work of railways and the methods of mathematical statistics. The problem of increasing the use efficiency of working hours of locomotive crews in freight traffic is considered in the article. Based on the statistical data processing of drivers' routes, the working hours' distribution of locomotive crews for different types of train operation in freight traffic for four locomotive depots was performed. During the research, a conditional division of the working time of locomotive crew by the type of work was performed, if the crew worked with trains of various categories. The algorithm for assigning the idle time and empty running of locomotive to certain types of train operation was also developed. The work originality lies in the fact that it improves the methods of analysis of the working hours' distribution of locomotive crews for certain types of train operation in freight traffic. The developed methods give an opportunity to evaluate the work specifics of individual locomotive depots and provide the initial data for planning the use of locomotives and the work and rest schedule of locomotive crews.
\end{abstract}

\section{Introduction}

A characteristic feature of the modern working conditions of railway transport in Ukraine is a critical level of traction rolling stock wear and an increasing misbalance between the number of locomotives and traffic volumes. In this regard, the task of improving the efficiency of using the existing fleet of locomotives and the staff of locomotive crews is of particular relevance. One of the ways to optimize and rationalize the transportation process is the development and implementation of a reliable system of operational planning of the work of locomotives and locomotive crews.

In Ukraine a system for traction train traffic, when the locomotive fleet and locomotive crews are distributed along the railway network and are assigned to the locomotive depot has been developed. The part of the railway network where the locomotives assigned to one locomotive depot turn around is called the locomotive operational area. Within long operational areas there may be intermediate points for locomotive turn-around, maintenance points, servicing terminals, locomotive crew change points, and the like. The section between the station of the main and turn-around depot is called the locomotive run. The locomotive operational areas may consist of one or several locomotive runs. The locomotive run may consist of one or more sections of the work of locomotive crews. In the process of its movement, the train can pass several sections of the work of locomotive crews and locomotive operational areas. The need to perform the regulated types of maintenance and servicing of locomotives, as well as compliance with the established norms of the working time of locomotive crews makes it necessary to stop the trains for their change.

When the standards for the operational work of Ukrzaliznytsia units are established for the planned month, calculations are made to determine the required fleet of locomotives for freight traffic and the attendant staff of locomotive crews, i.e., they are planned monthly. The planning provides for:

- calculation of the daily average attendant staff of locomotive crews for the mastering of the freight traffic volumes specified in the plan for the month;

\footnotetext{
*Corresponding author:dmytro.kozachenko@,outlook.com
} 
- the distribution of existing staff of locomotive crews in the assignment point over the work sections, types of movement and the types of work in order to bring its size in line with the upcoming workload;

- clarification of the annual holidays schedule for locomotive crews on the upcoming month.

Operational planning and management of the work of locomotives and locomotive crews at different levels is carried out by locomotive dispatchers of railway within the railway, locomotive dispatchers within the divisions of railway transportations and duty officers of locomotive depots. The development of methods for solving the problem of finding rational train servicing options by locomotives and crews has a rather long history and a significant number of scientific works are aimed at its solution. One of the first mathematical methods for solving this problem was proposed in the 60 s of the 20th century. In the work [1] by Charnes and Miller used linear programming for the assignment of crew-engine pairings to a set of potential trips to provide each train in a given schedule with sufficient resources. Bartlett in [2] gave an algorithm for minimizing fleet size based on the idea that, for a fixed time horizon, this objective is tantamount to minimizing total idle time.

In the works [3] by Cordeau et al. and Piu and Speranza [6] two types of locomotive planning models were identified: Single and Multiple. Single locomotive planning models assume that there is only one type of locomotive available for assignment and train is drived by only one locomotive. Multiple locomotive planning models assume that one or several locomotives can service each train; herewith there are several types of locomotives. In the work [4] the problem of servicing the train movement of the Italian railways is considered and an algorithm for its solving is presented. In the work [5] Vaidyanathan et al. presented an algorithm for solving the task of planning the work of locomotives for USA railways. In the work [5] Teichmannet al. presented an algorithm for solving the task of planning the work of locomotives for Czech railway.

The studies aimed at solving the problems of train maintenance by locomotives and locomotive crews for the conditions of the Russian Federation are presented in the works [8-10]. It should be noted that the presented models and methods of planning the work of locomotives and locomotive crews are designed for cases when the train schedule is known. At the same time, the railway transport operation is largely influenced by random factors. In this regard, the train movement is characterized by significant monthly, daily and intra-day non-uniformity. At the same time, the occupation or non-occupation of train path by a freight train is a random event. Therefore, the problem of planning and operational planning of the work of locomotives and locomotive crews should be considered both in a dynamic and stochastic formulation. However, the lack of currently functioning models for constructing a graph of the predicted turn-around of locomotives and locomotive crews for a monthly period does not allow solving the problem by the method of transportation process simulation, therefore the index method remains the basic method; based on the formation of the working time expenditures of locomotive and locomotive crews' work according to statistical data for the past similar period. To construct simulation models and check their adequacy, it is necessary to evaluate the actual working conditions of railway transport and establish the distribution of the working time of locomotives and locomotive crews by the types of work when servicing trains of various categories.

\section{Methodology}

The document that makes it possible to establish the working time distribution of the locomotive crews when servicing trains of various categories is the driver's route. It is filled by the locomotive driver and processed programmatically by entering the main indicators using the software that provides functioning of the automated working station processing the driver's route (WS DR). The driver's route is the main document for the calculation and accounting of the operational work of locomotives, fuel and lubricants and electricity consumption, working time and wages of locomotive crews.

The main sections of the driver's route are as follows: 1. Data on the traction rolling stock (TRS) and the staff of locomotive crew.

2. Information on the working time of the TRS and the locomotive crew.

3. Data on the locomotives operating in different connections, such as pushing or double heading.

4. Electricity and fuel consumption data.

5. Data on the movement, weight of the train and the shunting operation performed.

Further, the locomotive and the locomotive crew during one travel are considered as a single whole.

Let us dwell in more detail on the sections containing information on the working time of the TRS and the locomotive crew, as well as on the use of locomotive with and without a train during the working hours of the locomotive crew.

The working time duration of the locomotive crew (travel time) in general can be determined by the expression [11]

$$
t_{\mathrm{d}}=t_{\mathrm{a}-\mathrm{ac}}+t_{\text {ac-dep }}+t_{\text {mov }}+t_{\text {id }}+t_{\text {arr-w.e }}
$$

where $t_{\mathrm{a}-\mathrm{ac}}-$ is the time interval between the moment of the locomotive crew appearance at the beginning of the working time and the moment of the locomotive acceptance, $\mathrm{h}$;

$t_{\text {ac-dep }}-$ is the time interval between the moment of locomotive acceptance and its departure with train, $\mathrm{h}$;

$t_{\text {mov }}$ - is the movement duration of locomotive with train or in single running at the service section, $\mathrm{h}$;

$t_{\text {id }}$ - is theidle time of locomotive with a train at intermediate stations and at the station, which is the boundary of the service section - at the point of turnaround, h;

$t_{\text {arr-w.e }}-$ is the time interval from the moment of locomotive arrival with train or in a single running to the final station until the work end of the locomotive crew. 
During one travel, depending on the characteristics of the service section, such as its length, the structure of train traffic volume, the fullness of the train movement schedule, and othersthe locomotive can be used both to service the trains of the same or different categories. The decision on how to use the locomotive is made by the dispatching staff, depending on the operational situation and the restrictions, taking into account the mode of operation of the locomotive crew and the locomotive mileage between maintenance and repair.

The sequence of technological operations performed by locomotive with locomotive crew during one travel can be formalized as a directed graph $G=(V, P)$, presented in Fig. 1. The vertices of the graph $v_{\Pi} \in V$ are the technological operations corresponding to certain states of locomotive, and the arcs of the graph $p \in P$ transitions from one state to another. Transitions are initiated by the person making the decision on the further use of locomotive.

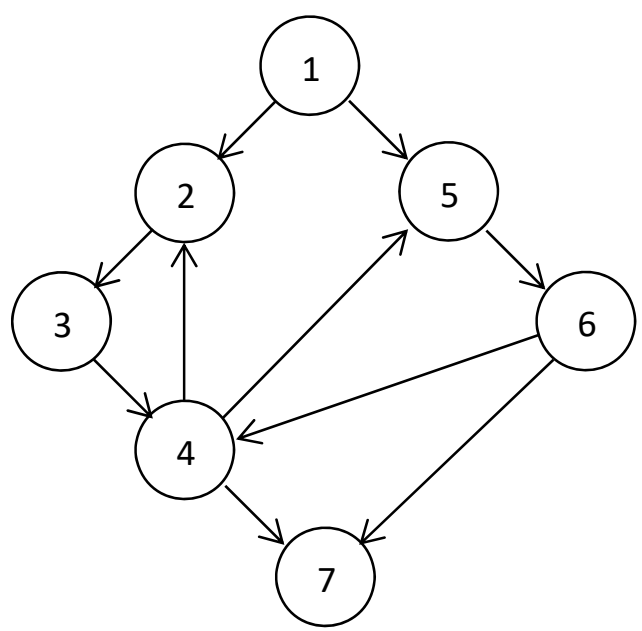

Fig. 1. Graphic representation of the use scheme of locomotive during one travel

Thus, the state «1» corresponds to the locomotive acceptance by the locomotive crew at the beginning of its work. After the crew's report on locomotive acceptance and readiness to carry out train work, a decision can be made to supply the locomotive to the freight train (state «2») or to dispatch the backup locomotive to another station to another train (state $« 5 »)$. In state «2» the locomotive is waiting for the train, then itis supplied to the train, and thenthe operations are performed to test the brakes, receive a form of warnings and documents, waiting for the possibility of departure and departure, at the time of which the transition to state «3» occurs - the locomotive moves with the train through the section to the destination station. In state «5», a single locomotive waits for the possibility of departure and is departed, at this moment there is a transition to state $\langle 6\rangle-$ backup running. When transiting to state $« 4 »$ from state $« 6 »$ one performs the operations with the locomotive upon arrival and supplies itto the freight train, i.e. transition to state «2». When transiting from state «3»to state «4»one also performs the stipulated technological operations with the locomotive upon arrival, and the further work plan may be as follows:

- supply to the freight train - the transition to state «2»;

- backup departure to another station to another freight train (state $« 5 »)$;

- end of work and delivery of locomotive (state $\langle 7 \gg)$.

The transition to state $\langle 7\rangle$ is possible from state $« 6 »$. This is possible if, after servicing one or several trains, the backup locomotive is dispatched to the station of the main or turn-around depot to further change of the locomotive crew. In this case, the locomotive crew at the locomotive delivers the locomotive and finishes the work.

Thus, this oriented graph can be used in a simulation model to simulate the sequence of individual operations with a locomotive during one travel.

The theory of locomotive operation includes three main ways of train servicing by locomotives - run, loop and ring, differing in the frequency of locomotive entry into the main depot, and three main ways of servicing locomotives by locomotive crews - calling system, job order system and using the personalized schedules.

A feature of the operation of locomotives and locomotive crews in the current conditions is that the main criterion for their use is the adherence to overhaul intervals. It should also be noted the lack of service sectionsassignment to the individual depots and the actual impersonality of the locomotive assigned depotsconcerning repairs. Maintenance and repair of locomotives can be performed not only in the assigned depots and the point of locomotives turn-around, but also in any other depot where such a need has arisen.

Another feature is that during one travel the locomotive can be used to service trains of various categories.

\section{Results}

The obtained statistical characteristics of the duration distribution of one travel and its main components for the four depots located at the site with different characteristics of the train traffic volume and the characteristics of its servicing were published in the article [11]. The average duration of a travel is fixed in the range from 8.8 hours for Znamenka depot to 11.30 hours for Odessa-Sortirovochnayadepot.

This is explained by the fact that Znamenka depot serves mainly through freight trains with and without processing with an insignificant share of district, cleanup and transfer trains. The Odessa-Sortirovochnaya depot is characterized by significant volumes of transfer trains at the junction, most of the locomotive crews working according to thepersonalized schedules with 12hour duration of working time.

The average duration values of the use of locomotives in train work - the time spent by the locomotive with the train ranges from 5.5 hours for Znamenka depot (62.5\% of the travel duration) to 7.44 hours for Nizhnedneprovsk-Uzel depot $(71.5 \%$ of the travel duration). 
The duration of locomotive movement with a train for Znamenka depot is 4.07 hours or $46.3 \%$ of the travel duration, for Nizhnedneprovsk-Uzel depot - 4.36 hours or $41.9 \%$ of the travel duration.

There is no the correlation relationship between the above indicators of the locomotives' use, and the correlation coefficient is $r=0.053$ and does not reach the minimum value of the loose couple according to the Chaddock scale (Fig. 2).

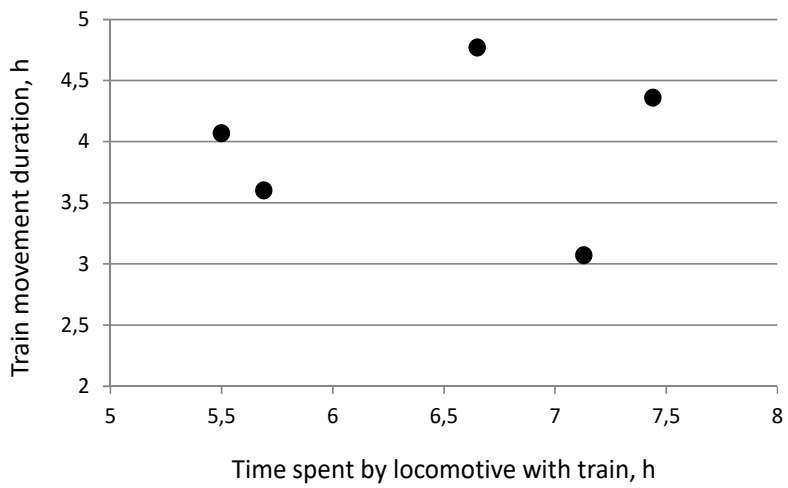

Fig.2. The dependence of the train movement duration on the time spent by locomotive with train.

Further studies have shown that the ratio of elements of train work - the time that a locomotive is with train and the time in motion with a train - have significant differences depending on the category of trains served by locomotives. Train driving on the extended runs of service cannot be compared, since such trains often move according to the schedule.

During one travel, the locomotive can serve trains of one category, while the calculation of statistical indicators has no differences from the calculation, the results of which are given above.

However, much of the travels is related to the driving of trains of various categories. In this regard, there is a need to develop a method of classifying the components of the working time of locomotives and locomotive crews as certain types of work when servicing trains of various categories.

The beginning of the work of locomotive crew is the moment of appearance $T_{\mathrm{a}}$ at work. After that, the crewgoes to locomotive and performs its acceptance in accordance with the rules and regulations at the moment $T_{\mathrm{ac}}$. The presence of the specified period of time $\left(t_{\mathrm{a}-\mathrm{ac}}=T_{\mathrm{ac}}-T_{\mathrm{a}}\right)$ is mandatory, and its duration must comply with the established standards $t_{\text {stand. The time }}$ interval $t_{\mathrm{a}-\mathrm{ac}}$ does not refer to a particular type of work.

The report on the locomotive readiness to perform work is the moment of the beginning of time period, which should be assigned to work with a train of a certain category. At the time of the locomotive crew's statement on the readiness to work $T_{\mathrm{ac}}$, the decision maker, as a rule, already knows further plan of work with the locomotive. The train category $k_{i}$ in the process of research is determined by its number $n_{i} \in \mathbf{N}(i=1,2,3$, $\ldots)$, and the vector of numbers Nand the order of their assignment to certain train categories is determined by the Order of direction of car traffic volumes and their organization into freight trains (Train formation plan).

The moment of the end of the time interval $W_{i}$, which is related to the work with the $i$-th train of a certain category $k_{i}$, is the moment $T_{\text {end } i}=T_{\text {unc } i}+t_{\text {tech }}$, where $T_{\text {unc } i}$ is the moment of the locomotive uncoupling from a train at the terminal station of the train running, $t_{\text {tech }}$ is the technological interval associated with the assignment of the train and transfer of train documents to the employee of the station technological centre. Since the driver's route does not contain information about the duration of the interval $t_{\text {tech, }}$, its duration in research is assumed to be 10 minutes.

It should be noted that the time moment $T_{\text {end } i}$ may be the starting point of the locomotive crew`s work with the next category of train $T_{\text {start } i+1}$ if the travel is not over. Obviously, for the first train, which the locomotive crew will work with at the start of shift $T_{\text {start } I}=T_{\mathrm{ac}}$, where $i=1$. Thus, the total work duration of locomotive crew $W_{i}$ with a certain train category $k_{i}$ is $W_{i}=T_{\text {end } i}-$ $T_{\text {start } i}$.

The analysis of the drivers' routes showed the presence of works related to the backup locomotives running for the subsequent work with trains of certain categories. In the performed studies, the duration of backup locomotives running $t_{\mathrm{b} i}$ is assigned to work with a train of the category whose servicing is the next technological element or state of the locomotive, i.e. $W_{i+1}=W_{i+1}+t_{\mathrm{b} i}$. In the case of backup locomotive running to the station of locomotive crew's change and the end of work, the interval $t_{\mathrm{b} i}$ is assigned to the type of work of a certain category of the previous train, i.e. $W_{i-1}=W_{i-1}+t_{\mathrm{b} i}$.

The statistical processing of drivers' routes showed the following results.

For the four depots considered, NizhnedneprovskUzel, Znamenka, Lviv-Zapad and OdessaSortirovochnaya, one can distinguish the categories of trains with which locomotives work throughout the entire travel, i.e. the locomotive serves one or two trains of only one category. These include through trains, unit trains and district trains. At the same time for OdessaSortirovochnayadepot,the routes for servicing the sections with diesel-electric and electric traction were analyzed. Some of these travels, from the total number of the analyzed ones, are in the range from 19.25 to $52.8 \%$ with a predominance of travels in which trains of a certain category are serviced.

Thus, for Znamenka depot, the number of travels when the locomotives served only district trains accounted for $24.1 \%$ of the total; for Lviv-Zapad and Nizhnedneprovsk-Uzel depots, dominate the travelswhenthrough trains were serviced $-29.64 \%$ and $34.6 \%$, respectively. Odessa-Sortirovochnaya depot in the electric traction is characterized by the minimum number of travels, when the locomotives serviced only through and unit trains $-3.87 \%$ of the total.

This confirms the need to take into account the specifics of the work of each locomotive depot.

The results of research of the duration of the main elements of the travel, when only trains of a certain category were serviced, are shown in Fig. 3. 


\begin{tabular}{|c|c|c|c|c|}
\hline \multirow[b]{2}{*}{ Depot } & \multirow[b]{2}{*}{$\begin{array}{c}\text { Train } \\
\text { category }\end{array}$} & \multicolumn{3}{|c|}{$\begin{array}{l}\text { Mathematical } \\
\text { expectation, } h\end{array}$} \\
\hline & & $\begin{array}{c}\text { Travel } \\
\text { duration, } \\
t_{\mathrm{d}}\end{array}$ & $\begin{array}{l}\text { Time } \\
\text { spent } \\
\text { with } \\
\text { train } \\
t_{\text {train }}\end{array}$ & $\begin{array}{c}\text { Movement } \\
\text { duration } \\
\text { with train } \\
t_{\text {mov }}\end{array}$ \\
\hline \multirow{3}{*}{$\begin{array}{c}\text { Nizhnedneprovsk- } \\
\text { Uzel }\end{array}$} & Through & 10.10 & 7.26 & 4.69 \\
\hline & Route & 9.10 & 5.07 & 3.16 \\
\hline & District & 8.60 & 5.59 & 3.74 \\
\hline \multirow{3}{*}{ Znamenka } & Through & 8.79 & 5.86 & 4.43 \\
\hline & Route & 7.81 & 5.04 & 3.96 \\
\hline & District & 7.25 & 4.34 & 3.35 \\
\hline \multirow{3}{*}{ Lviv-Zapad } & Through & 8.51 & 5.87 & 4.47 \\
\hline & Route & 10.17 & 7.12 & 5.57 \\
\hline & District & 10.20 & 6.96 & 4.19 \\
\hline \multirow{3}{*}{$\begin{array}{l}\text { Odessa- } \\
\text { Sortirovochnaya, } \\
\text { electric traction }\end{array}$} & Through & 7.95 & 4.81 & 3.66 \\
\hline & Route & 8.07 & 5.03 & 3.52 \\
\hline & District & 7.82 & 4.97 & 3.04 \\
\hline \multirow{3}{*}{$\begin{array}{l}\text { Odessa- } \\
\text { Sortirovochnaya, } \\
\text { diesel-electric } \\
\text { traction }\end{array}$} & Through & - & - & - \\
\hline & Route & 8.50 & 4.28 & 3.03 \\
\hline & District & 11.16 & 6.88 & 4.27 \\
\hline
\end{tabular}

Fig. 3. Duration of the main elements of the travel

The duration of time spent by locomotive with train $t_{\text {train }}$ and the duration of movement with train $t_{\text {mov }}$ correlates with the total durationof travel $t_{\mathrm{d}}$ for trains of all categories; according to the Chaddock scale they have a very significant relationship. As an example, Fig.4 shows the field of points and correlation coefficients.

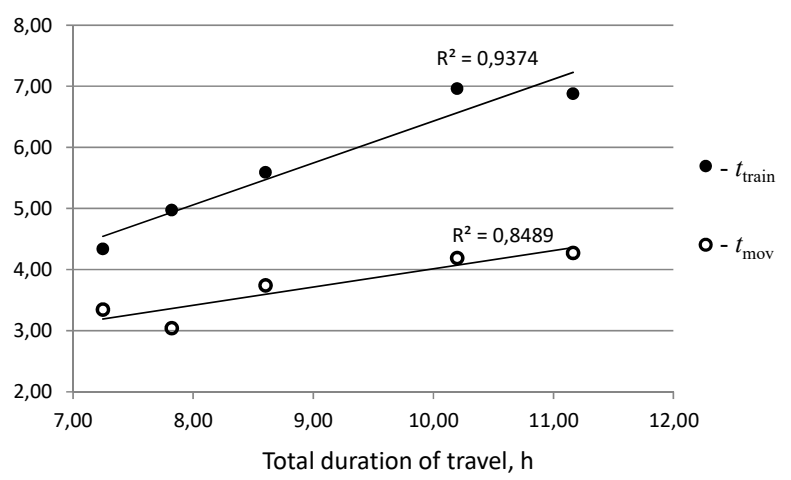

Fig. 4. Dependencies of time spent by locomotive with train $t_{\text {train }}$ and the duration of movement with train $t_{\text {mov }}$ on the travel duration $t_{\mathrm{d}}$

Using the methods of regression analysis we obtained analytical dependencies of the type $t_{\mathrm{d}}=f\left(t_{\text {train }}\right)$ and $t_{\mathrm{d}}=f\left(t_{\mathrm{mov}}\right)$, which are convenient to use when simulating the work of locomotive crews. Fields of points and analytical models are presented in Fig. 5.
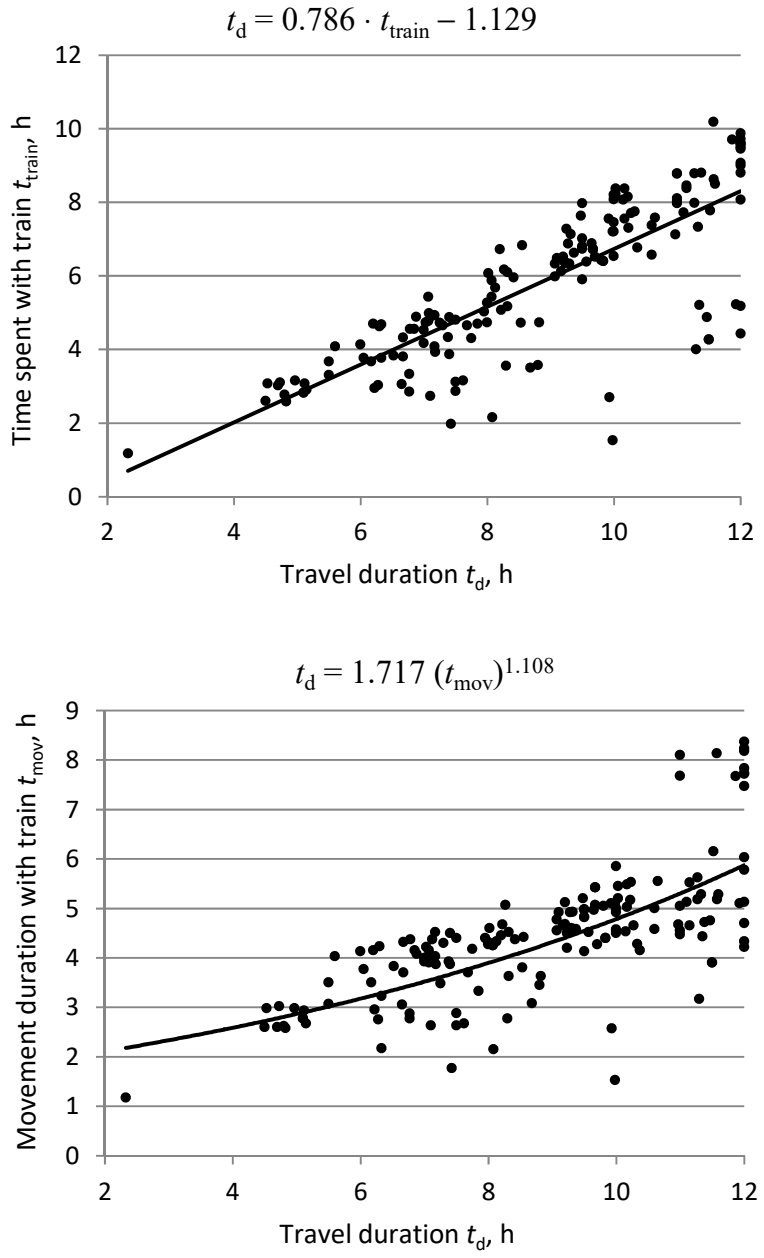

Fig. 5. Fields of points and corresponding analytical models

Analysis of the values of $t_{\text {train }}, t_{\text {mov }}$ and $t_{\mathrm{d}}$ allowed us to obtain their statistical parameters, as well as the nature of distribution. The results of the analysis are given in Fig. 6, and histograms and distribution laws of the indicated values are shown in Fig. 7.

\begin{tabular}{|c|c|c|c|}
\hline \multirow{2}{*}{$\begin{array}{c}\text { Statistical } \\
\text { parameters }\end{array}$} & \multicolumn{3}{|c|}{ Time characteristic } \\
\cline { 2 - 4 } & $\begin{array}{c}\text { Travel } \\
\text { duration, } \\
t_{\mathrm{d}}\end{array}$ & $\begin{array}{c}\text { Time spent } \\
\text { with train } \\
t_{\text {train }}\end{array}$ & $\begin{array}{c}\text { Movement } \\
\text { duration with } \\
\text { train } t_{\text {mov }}\end{array}$ \\
\hline$t_{\text {min }}, \mathrm{h}$ & 2.33 & 1.17 & 1.17 \\
\hline$t_{\text {max }}, \mathrm{h}$ & 12.00 & 10.18 & 8.37 \\
\hline $\begin{array}{c}\text { Mathematical } \\
\text { expectation } m_{t}, \mathrm{~h}\end{array}$ & 8.789 & 5.855 & 4.430 \\
\hline $\begin{array}{c}\text { Mean-square } \\
\text { deviation } \sigma_{t}, \mathrm{~h}\end{array}$ & 2.130 & 2.030 & 1.806 \\
\hline $\begin{array}{c}\text { Distribution law } \\
\text { normal }\end{array}$ & normal & gamma \\
\hline Chi-square test & 2.42 & 8.77 & 9.23 \\
\hline
\end{tabular}

Fig. 6. Statistical parameters of duration of the main elements of the travel 
a)

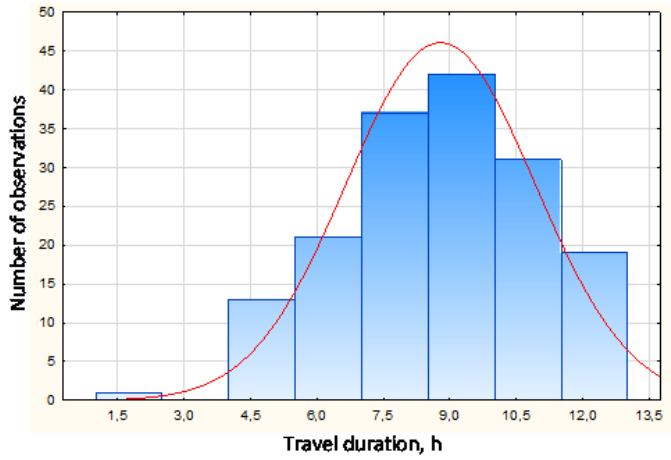

b)

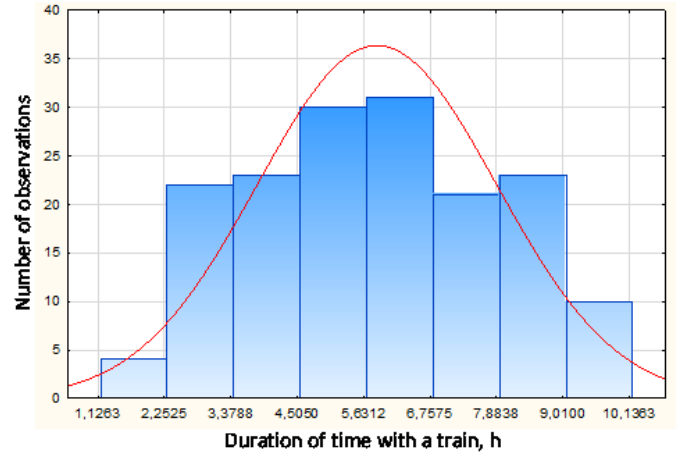

c)

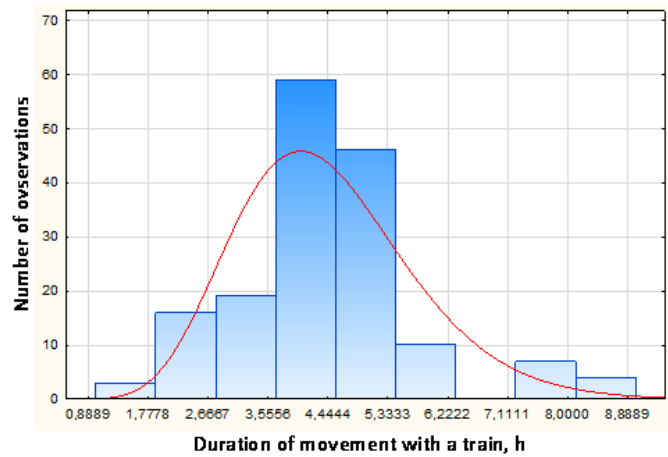

Fig. 7. Distribution histograms oftravel duration $t_{\mathrm{d}}(\mathrm{a})$, duration of stay of locomotive crew with a traint $t_{\text {train }}$ (b) and movement duration of locomotive crew with a $\operatorname{train} t_{\text {mov }}$ (c)

Similar dependencies were obtained for the travels, during which the locomotive serviced different categories of trains. In addition to the categories discussed above, they should include clean-up, transfer trains and for some depots an insignificant number of pick-up and pick-up-district trains. A feature of such travels is that an additional element appears - backup locomotive running. Of the total service time of a particular category of train during the travel, backup running ranges from $1.5 \%$ for through trains, to $28.6 \%$ for transfer trains, and up to $50 \%$ for pick-up trains.

Another feature of such travels is that the locomotive performance is generally lower than that when servicing only one category of trains during the travel.

Similar to the results of the studies presented above, we can state that there is correlation relationship between the servicing time of a train of certain category $t_{k}$ and the duration of movement with a train of this category $t_{\text {mov } k}$; however, for various depots according to the Chaddock scale, this relationship is somewhat lower and significant.

As an example Fig. 8 shows the distribution histogram of the duration of locomotive crew's stay with a train, when it served the trains of different categories during the travel.

\section{Scientific novelty and practical significance of work}

The work originality lies in the fact that it improves the methods of analysis of the working hours` distribution of locomotive crews for certain types of train operation in freight traffic. The developed methods give an opportunity to evaluate the work specifics of individual locomotive depots and provide the initial data for planning the use of locomotives and the work and rest schedule of locomotive crews.

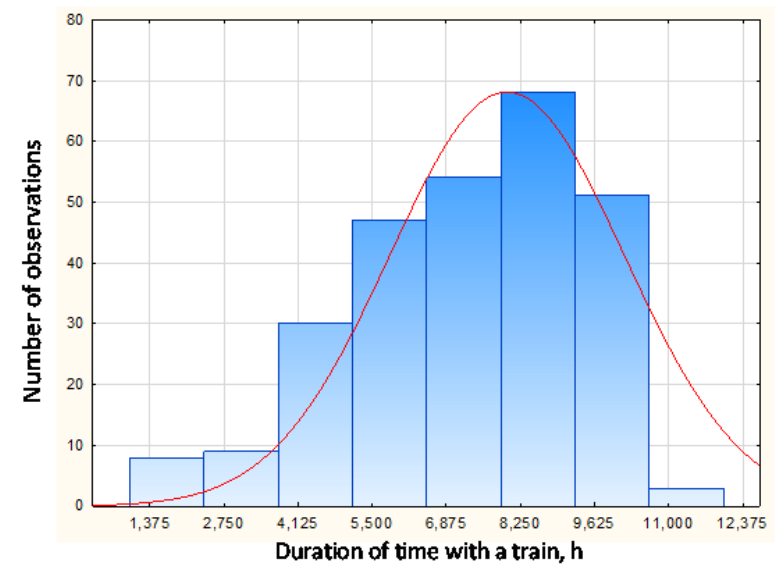

Fig. 8. Duration of stay of locomotive crew with a train

\section{Conclusions}

As a result of the research, the following conclusions were obtained.

1. The graphical formalization of the locomotive use scheme for one travel as a directed graph can be used in a simulation model to simulate the sequence of individual operations with the locomotive.

2. There are differences in travels, during which the locomotive serves trains of only one category and trains of different categories, in terms of the duration distribution of individual states of the locomotive, which requires a conditional division of such travels. 
3. We proposed a method for assigning the travel time components of a locomotive crew to the trains of various categories that were serviced during the travel.

4. Using the methods of regression analysis, we obtained analytical dependencies, which are convenient to use when simulating the work of locomotives and locomotive crews.

5. Statistical parameters were obtained, as well as the distribution nature of the values that are components of the travel duration of locomotive crew.

\section{References}

1. A. Charnes, M. H. Miller A model for the optimal programming of railway freight train movements, Management Science, Vol. 3, 74-92 (1965).

2. T. E. Bartlett, An Algorithm for the Minimum Number of Transport Units to Maintain a Fixed Schedule, Naval Res. Logist. Quart, Vol. 4,139-149 (1957).

3. J. F. Cordeau, P. Toth, D. Vigo, A survey of optimization models for train routing and scheduling, Transportation Science, Vol. 32, 380404 (1998).

4. A. Caprara, M. Fischetti, P. Toth, D. Vigo, P. L. Guida, Algorithms for Railway Crew Management, Math. Programming, Vol. 79, 125-141 (1997).

5. B. Vaidyanathan, R. K. Ahuja,J. B. Orlin, The locomotive routing problem, Transportation
Science, Vol. 42, Iss. 4, $492-507$ (2008). doi: $10.1287 /$ trsc. 1080.0244

6. F. Piu, M. G. Speranza, The locomotive assignment problem: a survey on optimization models, International Transactions in Operational Research, Vol. 21, 327-352 (2014). doi: 10.1111/itor.12062

7. D. Teichmann, M. Dorda, K. Golc, H. Binova, Locomotive Assignment Problem with heterogeneous vehicle fleet and hiring external locomotives, Mathematical Problems in Engineering, 1-7 (2015) doi: 10.1155/2015/583909

8. P. Kozlov, E. Timukhina, N. Tushin, Coordination of locomotives turnover and servicing modes, Transport problems, Vol. 13, Iss.1, 19-26 (2018). doi: 10.21307/tp.2018.13.1.2

9. P. A. Kozlov, S. P. Vakulenko, Optimization of locomotive work modes with the use of system Labyrinth, World of Transport and Transportation, No. 4, 10-14 (2016). [in Russian]

10. P. A. Kozlov, S. P. Vakulenko, Optimization of locomotives turnover for given train flows, Railway Transport, No. 10, 34-37 (2016). [in Russian]

11. Y. Grimak, Analysis of the distribution of elements of working time of locomotive brigades within the trips in the freight traffic, Transport systems and transportation technologies, No. 17, 4-8 (2019). [in Ukrainian] 